\section{Apuntes sobre la arquitectura de los hogares y hornos domésticos altomedievales del centro de la península Ibérica (siglos v-vIII d.C.)}

\section{Notes on the architecture of early medieval domestic hearths and ovens in the center of the Iberian Peninsula $\left(5^{\text {th }}-8^{\text {th }} A D\right)$}

\author{
Alfonso Vigil-Escalera Guirado* \\ Universidad del País Vasco UPV/EHU
}

\section{Resumen}

El presente trabajo reclama la atención sobre la arquitectura de las estructuras de combustión de carácter doméstico (hogares y hornos) presentes en los asentamientos rurales de los primeros siglos altomedievales en el centro peninsular. A través de un somero repaso de las principales características de las mismas, tal y como se desprende de la documentación de un puñado de yacimientos de distinta cronología, se exponen los principales problemas de identificación de este tipo de estructuras y algunas posibilidades de categorización morfológica. Finalmente se apunta la relevancia y necesidad de una adecuada sistematización e interpretación de estas estructuras con objeto de comprender el funcionamiento del espacio doméstico campesino en su conjunto y su proceso de transformación a lo largo del tiempo.

Palabras clave: Arqueología altomedieval, asentamientos campesinos, arquitectura doméstica, estructuras de combustión, elaboración de alimentos.

\section{Abstract \\ This paper calls for attention to the architecture of domestic combustion structures (hearths and ovens) in the rural settlements of central Spain during the first early medieval centuries. Some of the major problems of identification and the possibilities of morphological categorization are outlined through a brief review of their main features, as is evident in data from a handful of sites from different periods. Finally the paper points out the relevance and need for proper systematization and interpretation of these structures in order to understand the functioning of the peasant domestic space as a whole and its transformation over time.}

Key words: Early medieval archaeology, peasant settlements, domestic architecture, fire structures, food processing.

\footnotetext{
"alfonso.vigilescalera@ehu.es

Investigador posdoctoral, Departamento de Geografía, Prehistoria y Arqueología, Universidad del País Vasco UPV/EHU. Este trabajo ha sido realizado en el marco del proyecto de investigación «La formación de los paisajes medievales en el Norte Peninsular y en Europa» (HUM 2009-07079) financiado por el Ministerio de Ciencia e Innovación, y de la actividad del Grupo de Investigación en Patrimonio y Paisajes Culturales/Ondare eta Kultur Paisaietan Ikerketa Taldea (IT315-10), financiado por el Gobierno Vasco.
}

\section{INTRODUCCIÓN}

Hogares y hornos constituyen los elementos básicos en torno los cuales se articula el espacio doméstico en la arquitectura tradicional. Esa centralidad contrasta con la escasa definición arqueológica que tales estructuras han recibido en la caracterización de la arquitectura doméstica rural, tanto de época clásica como altomedieval, en nuestro territorio. A través de la exposición de una serie de casos pasaremos revista a algunos problemas de conceptualización e interpretación funcional de diversas estructuras de combustión, hogares y hornos domésticos, en el ámbito rural de la región madrileña.

La extensión de la práctica arqueológica, en especial de la de carácter preventivo, contractual o comercial, ha permitido durante los últimos 20 años realizar un formidable avance en el conocimiento de la sociedad altomedieval, especialmente en el ámbito rural (Quirós 2007, 2009). Una de sus consecuencias destacables ha sido la reestructuración de los principales focos de interés de la investigación histórica, hasta el punto de que se haya llegado a hablar de un giro arqueológico en el estudio del campesinado (Escalona 2009). A pesar del extraordinario volumen y entidad de los nuevos descubrimientos, la publicación y sistematización del nuevo corpus de datos sigue siendo un asunto pendiente. Los principales resultados han ido concretándose en la delineación de las secuencias de desarrollo de las producciones cerámicas (Caballero, Mateos, Retuerce 2003; Alba, Gutiérrez Lloret 2008), parte troncal ineludible para la generación de cronologías ajustadas, en el esclarecimiento de la estructura del poblamiento rural (Quirós, Vigil-Escalera 2006; Vigil-Escalera 2007a), en un decidido impulso a todo lo relacionado con la arquitectura doméstica (Gutiérrez Lloret 2000; Azkarate, Quirós 2001; Quirós 2011) o incluso en la definitiva integración de los datos bioarqueológicos en el análisis completo del registro arqueológico (Quirós 2012), por poner solo algunos ejemplos.

En el ámbito de la arquitectura doméstica, el énfasis ha estado centrado sobre todo en las técnicas y materiales constructivos, la morfología de los edificios, en la variabilidad regional y en los posibles cambios observables en los registros a partir del siglo VIII d.C. Resulta extraño que un elemento central en la arquitectura del espacio doméstico y en su precisa articulación como es el hogar, o más genéricamente, las estructuras para el manejo del fuego, hayan recibido durante estos últimos años tan escasa atención ${ }^{1}$. A ellas estarán dedicadas estas páginas.

\footnotetext{
Es significativo que en la amplia relación de síntesis sobre la arquitectura doméstica altomedieval realizada a partir de la documentación de las excavaciones en la Catedral de Vitoria, los hogares constituyan una nota a pie de página
} 
Las estructuras domésticas de combustión se distinguen de aquellas destinadas a actividades artesanales por caminos en muchos casos indirectos: bastantes veces por su emplazamiento en relación con la vivienda, otras por sus rasgos estructurales o constructivos, pero casi siempre por no presentar residuos, escorias o desechos de cualquier clase de actividad productiva. Como señala BruleyChalbot (2007), «el peor enemigo para la identificación de las estructuras de combustión es el arrasamiento. ¿Cómo distinguir un horno de un hogar cuando se conserva únicamente una rebanada del suelo?» La cuestión estriba en determinar si dos procesos de cocción diferentes pueden producir un mismo tipo de huella arqueológica. "Una solera, es decir, una superficie horizontal tostada, parece la resultante de un horno cuando alcanza una rubefacción homogénea superior a 3 o $4 \mathrm{~cm}$, siendo necesario para ello la presencia de una bóveda. Sin embargo, algunas placas de hogar documentadas en contexto de vivienda asemejan a veces bastante a la solera de un horno" (Bruley-Chalbot 2007). A este autor se debe uno de los escasos trabajos de investigación centrados en el análisis arqueológico de esta clase de estructuras en el periodo que nos ocupa (Id: 1997).

Hogar puede ser cualquier lugar donde se haya hecho fuego, si bien a efectos arquitectónicos (y arqueológicos) el hogar se definiría como el sitio donde se controla el fuego, ya sea para cocinar, calentar, alumbrar o una combinación de todas esas funciones (Cañavate 2008: 107). El tipo más básico no requiere ningún arreglo particular, pudiendo adoptar en planta formato circular, rectangular, cuadrangular o irregular. Si se dejan las cenizas en su sitio, éstas forman una capa aislante entre el suelo y el fuego, y el primero apenas quedará marcado. Los hogares pueden acondicionarse con una solera de arcilla que forme una placa de hogar, y a veces delimitarse con piedras o tejas que constriñen el fuego. Este es el caso más habitual en la arquitectura de casas y cabañas. A mayor recurrencia en el uso, mayor rubefacción se genera y más probable es que pueda llegarse a identificar la estructura, afirma BruleyChalbot a partir de los casos contemplados del Norte de Francia. Los hogares puede también estar excavados o

(Azkarate, Quirós 2001: nota 22). Igualmente, en el voluminoso estado de la cuestión sobre los asentamientos rurales altomedievales del Norte de Francia, el análisis de estas estructuras apenas ocupa un par de páginas (Peytremann 2003: 292-5). Dignos de reseña serían el riguroso análisis que estas estructuras han merecido en el yacimiento albaceteño del Tolmo de Minateda (Cañavate 2008) y el reciente trabajo de Roig (2009: 235-237). También Alba (1997) y Vizcaíno (2007) han reparado en estas estructuras en sus respectivos trabajos sobre Mérida y Cartagena. El estudio sintético de referencia sobre estas formas de arquitectura doméstica en el ámbito andalusí fue abordado años atrás por A. Bazzana (1996). rehundidos y a menudo las cenizas se dejan en el fondo. Las paredes quedan entonces rubefactadas, pero no así la base. En estos casos, el hogar podría ser confundido con un horno.

Los hornos se encuentran representados mayoritariamente en nuestros registros por ejemplares de cámara hemisférica excavada parcial o totalmente en el sustrato geológico. La cavidad sirve a la vez de cámara de fuego y de cocción. El horno se asocia siempre a una fosa de trabajo delante de su embocadura, que permite la manipulación en el interior de la cámara. La configuración de ese espacio, como veremos más adelante, determina algunas de las principales variantes discriminatorias para la clasificación de los hornos. Varios hornos pueden instalarse en torno a una misma fosa, normalmente de forma consecutiva. Los casos de empleo en batería (simultáneamente) serían raros, según Bruley-Chalbot (2007) y en eso coincide también el análisis de los registros del interior peninsular. Las reparaciones y acondicionamiento de estas estructuras son habituales y a veces bien visibles, sobre todo en lo que respecta a la refacción de las soleras. En algunos casos una cámara de horno amortizada puede servir de espacio de trabajo para un nuevo horno excavado en uno de sus lados. La disposición de agujeros de poste en el entorno de la cámara o del ambiente de trabajo testimonia la existencia de cubiertas. Algunas de las instalaciones solo se explican probablemente en función de la comodidad del usuario: banquetas, sistemas de acceso...

Los criterios tenidos en consideración por el citado autor para establecer la variabilidad tipológica de los hornos han sido las siguientes: las dimensiones de la solera (longitud, anchura, ancho de la embocadura...), su morfología (ovalada, circular, irregular...), su inclinación (plana, pendiente hacia la embocadura o hacia el fondo) y la altura de la bóveda o la de la embocadura (si fuera posible su determinación). La bóveda puede estar completamente excavada en el sustrato o puede estar parcial o totalmente construida (en piedra, en tierra o mixta), alternativa que se explica en parte por la naturaleza del sustrato geológico (excavabilidad y resistencia).

Su funcionamiento resulta muy similar al del horno tradicional de pan que aún conocemos en la actualidad. El fuego se hacía en el centro o cerca de la embocadura, como testimonia el mayor espesor de la capa de rubefacción en esas zonas. Las brasas no parecen haber sido retiradas hacia los bordes de la solera del horno sino extraídas de su interior cuando el horno estaba suficientemente caliente para aprovechar así la cualidad irradiante de la arcilla. La embocadura debía estar cerrada para que el calor no se 
perdiera con rapidez, pero la gestión del proceso podía resultar problemática, ya que un cierre hermético haría complicada la vigilancia de la cocción. Los análisis efectuados en distintas soleras revelan que la temperatura alcanzada estaría entre los $400^{\circ}$ y los $500^{\circ} \mathrm{C}$ (Roig 2009: 236), aunque en algún caso esa temperatura podría haber sido superior ${ }^{2}$.

El corpus de estructuras domésticas de combustión recopilado por Bruley-Chalbot (2007) ascendía en la región francesa de Île-de-France a unos 600 individuos, revelando otros dos tipos en activo junto a los hornos hemisféricos. A pesar de las diferencias en lo que concierne a la morfología, la función culinaria de éstos es indudable. El primer grupo estaría formado por estructuras con cámara de cocción tubular o cónica (a veces denominadas 'en forma de cigarro'). Tienen solera plana, las paredes redondeadas y su altura no es superior a los $30 \mathrm{~cm}$. Estos ejemplos solo se han constatado en sitios de cronología bajoimperial. El segundo tipo sólo ha aparecido en el yacimiento de Saint-Pathus, al Oeste de Ile-de-France, ocupado ininterrumpidamente desde el siglo III al x d.C. Entre los hornos documentados se encuentran algunos de pequeñas dimensiones y planta alargada, cámara menos cónica que las del caso antes citado y con la solera bien cocida, con resaltes a menudo en la parte trasera de la cámara y espesores de rubefacción bastante elevados (10$15 \mathrm{~cm}$ ). Las dataciones arqueomagnéticas probarían su uso exclusivo en época merovingia. Puede tratarse, según el autor, de una peculiaridad funcional de interpretación ignota o igualmente de una especificidad regional. Una de las carencias estructurales presentes en la documentación arqueológica de estas estructuras en los yacimientos del interior peninsular es precisamente la práctica inexistencia de análisis específicos.

Los hornos hemisféricos considerados, como los de pan, pueden albergar otra clase de funciones culinarias o extraculinarias. Podrían usarse, por ejemplo, para secar o tostar productos cuando la temperatura disminuye. Sin embargo, la evidencia arqueológica a este respecto (el uso cotidiano de los hornos, los alimentos preparados en ellos), es en la práctica inexistente. Dos ejemplos de pan carbonizado hallados en el sitio de Louvres 'Orville' (Gentili 2000) revelaron una masa levantada con una harina más o menos terrosa, pero su recuperación no estuvo asociada a estructuras de cocción.

\footnotetext{
2 Para el horno documentado en Can Roqueta (Sabadell, Barcelona) se señala una temperatura máxima de $850^{\circ} \mathrm{C}$, suponiéndose un uso comunal y su relación con la producción cerámica, aunque sus rasgos responden en todo a la categoría doméstica aquí tratada (Terrats 2009: 309, Fig. 3).
}

Por cuanto respecta a las dimensiones de las soleras se han distinguido en el citado corpus cuatro grupos: el primero con entre 0,1 y $0,7 \mathrm{~m}^{2}$, el segundo con entre 0,8 y $1,6 \mathrm{~m}^{2}$, el tercero con entre 1,7 y $3,1 \mathrm{~m}^{2}$ y el grupo 4 con soleras de entre 3,5 y $8,9 \mathrm{~m}^{2}$. Los hornos de grandes dimensiones (grupos 3 y 4) existen durante todos los periodos contemplados, entre el Bajo Imperio y el siglo XII. Sin embargo, se constata que a partir del siglo X sólo aparecen estos tipos mayores, aumentando el espesor de la capa rubefactada con el tiempo y reduciéndose el tamaño de la embocadura y el número de estructuras de cocción en el seno de los asentamientos. Durante el Bajo Imperio suelen aparecer uno o dos grandes hornos de gran tamaño. Aunque presumiblemente nos encontremos ante explotaciones de carácter familiar, no se excluiría una gestión centralizada de los mismos por parte de un eventual propietario o administrador. En los yacimientos franceses de época merovingia analizados por Bruley-Chalbot (2007), las aldeas cuentan con numerosos hornos, dispersos o agrupados en unidades de explotación con la vivienda. Después, las estructuras tienden a formar grupos, en sectores específicos, y su número se reduce. En los yacimientos de los siglos XI-XII, los hornos suelen ser estructuras únicas, revistiendo un probable carácter colectivo.

\section{HOGARES Y HORNOS DOMÉSTICOS EN CONTEXTOS DE CRONOLOGÍA ROMANA (SS. I-IV D.C.)}

Los datos de una serie de yacimientos rurales de época romana localizados en el mismo ámbito territorial del centro peninsular (Figura 1) se emplearán como contraste a efectos de caracterizar las eventuales novedades que revela el registro arqueológico de época altomedieval. Por desgracia, hasta la fecha no han sido documentados hornos, y tan sólo los hogares ubicados en el interior de las viviendas servirán a efectos comparativos.

\subsection{La casa de patrón itálico de La Indiana (Pinto, Madrid)}

El yacimiento de La Indiana, excavado parcialmente durante el proceso de desarrollo urbanístico de la localidad de Pinto hacia el Norte entre 1996 y 2001 por distintos equipos y empresas, nunca ha sido objeto de una edición integral. Presenta numerosas ocupaciones solapadas relativas a distintos periodos, desde la prehistoria a época medieval. Durante el año 1997, la excavación en extensión de una de las parcelas deparó el hallazgo de un interesante edificio levantado hacia mediados del siglo I d.C. según patrones claramente romanos (Figura 2). A pesar de que 


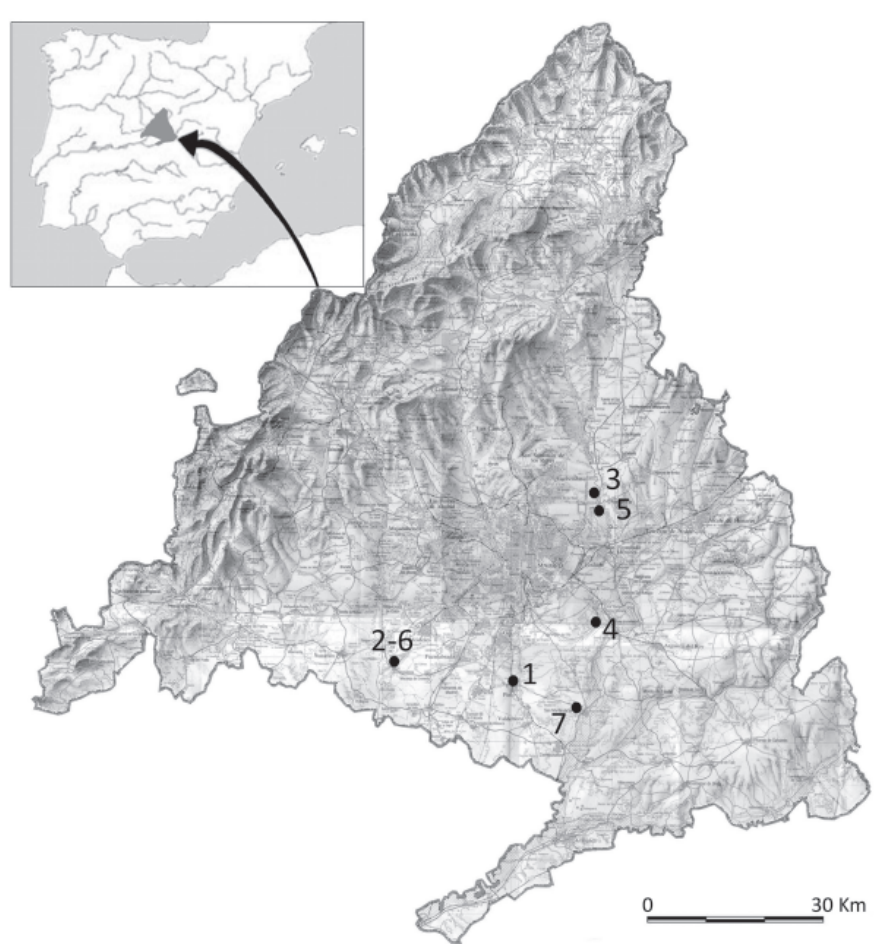

Fig. 1. Localización de los yacimientos citados en el texto. 1, La Indiana; 2, Zarzalejo; 3, El Rasillo; 4, Congosto; 5, La Huelga; 6, El Pelícano; 7, Gózquez

estuvo en uso hasta inicios del siglo III d.C., su estructura original no sufrió excesivas modificaciones (Vigil-Escalera 2007b). El intenso expolio de material constructivo durante la Alta Edad Media ${ }^{3}$ afectó especialmente a los zócalos de piedra, aunque de modo muy puntual, sin alterar los derrumbes de las cubiertas de teja del interior de sus diversas estancias.

Se distinguieron en su interior un ambiente interpretado como cocina (H6.2), huellas de rubefacción de planta circular en el centro de las habitaciones orientales (H1, H7, H6.3) y un posible hogar de planta cuadrangular sobre un banco de adobe en el patio (H9). Aunque no pueda afirmarse con rotundidad que todos esos puntos de fuego hayan estado en uso al mismo tiempo, se comprueba en este sitio la variabilidad de distintos elementos diferenciables por sus rasgos constructivos ${ }^{4}$. Es probable que cada una de ellas sirviese a fines específicos, con posibles estructuras de calefacción (correspondientes con las huellas de fuego detectadas en los ambientes del ala Este) diferenciadas del lugar específico asociado funcionalmente a la preparación de alimentos.

${ }^{3}$ Noticias publicadas sobre la ocupación altomedieval del yacimiento, tanto del asentamiento como de los espacios funerarios asociados, pueden consultarse en Morín et al. 2007, Vigil-Escalera 1999, 2007a.

${ }^{4}$ Se ha excluido de la descripción una fosa-horno excavada en $\mathrm{H} 7$, asociada a labores de forja que tuvieron lugar inmediatamente antes del abandono del edificio.

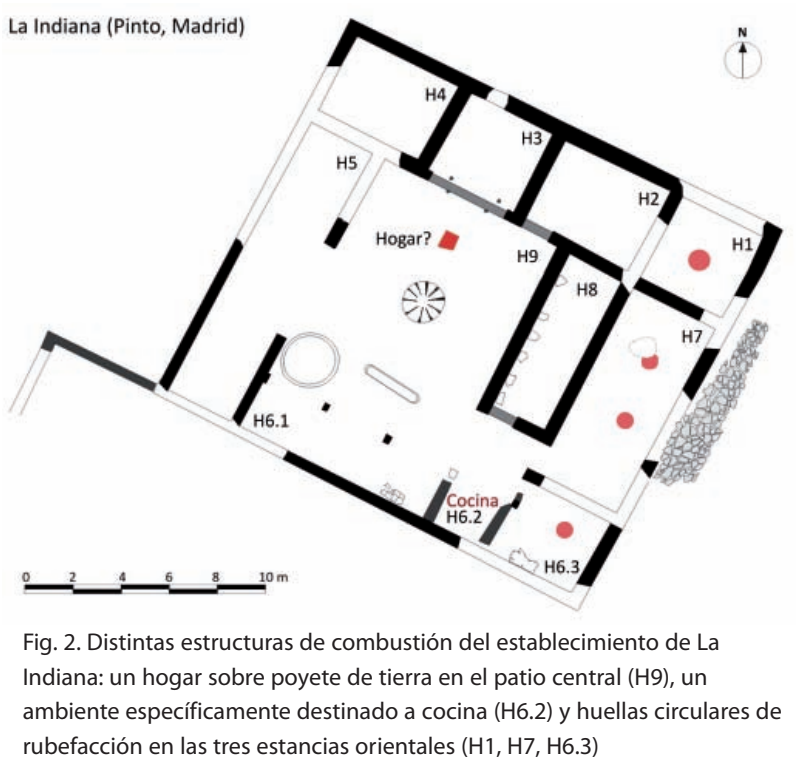

\subsection{La casa altoimperial de Zarzalejo (Arroyomolinos, Madrid)}

En el yacimiento de Zarzalejo, al Sur del arroyo de Los Combos, municipio de Arroyomolinos, se excavó por procedimiento de urgencia durante los años 2003-2004 un complejo de edificaciones de cronología imperial romana en torno a un área común abierta (Hernández et al. 2004). Los distintos bloques de construcciones incluyen espacios de uso residencial y productivo o de almacenamiento, y estuvieron en uso, de acuerdo con el análisis del repertorio cerámico, entre inicios del siglo II d.C. y mediados o el tercer cuarto del siglo III d.C.

Se documentaron hogares o manchas de fuego en distintas habitaciones. A excepción del hogar del ambiente A13, cuya descripción detallada ofreceremos a continuación (Figura 3), el resto son simples huellas más o menos circulares o irregulares de rubefacción, a veces en posición centrada, otras adosadas a los muros perimetrales u ocupando alguna esquina. Las edificaciones dispuestas en la zona Norte parecen haber tenido relación con actividades productivas o de almacenamiento. El edificio situado al Suroeste tenía una sala destinada al pisado de la uva (lacus) y un depósito de recogida de líquidos. El bloque que ocupa el lado SW del patio central responde preferentemente a función residencial.

El hogar localizado en el centro de A13 tiene planta rectangular (114 por $98 \mathrm{~cm}$ ). Una solera de ladrillos (UE 1235) se dispone sobre un banco de adobe a unos $18 \mathrm{~cm}$ sobre la cota del suelo de tierra apisonada (UE 13471348). La habitación mide 6,90 metros de largo por 4,50 de ancho, lo que deja unos $31 \mathrm{~m}^{2}$ de superficie útil (Figu- 


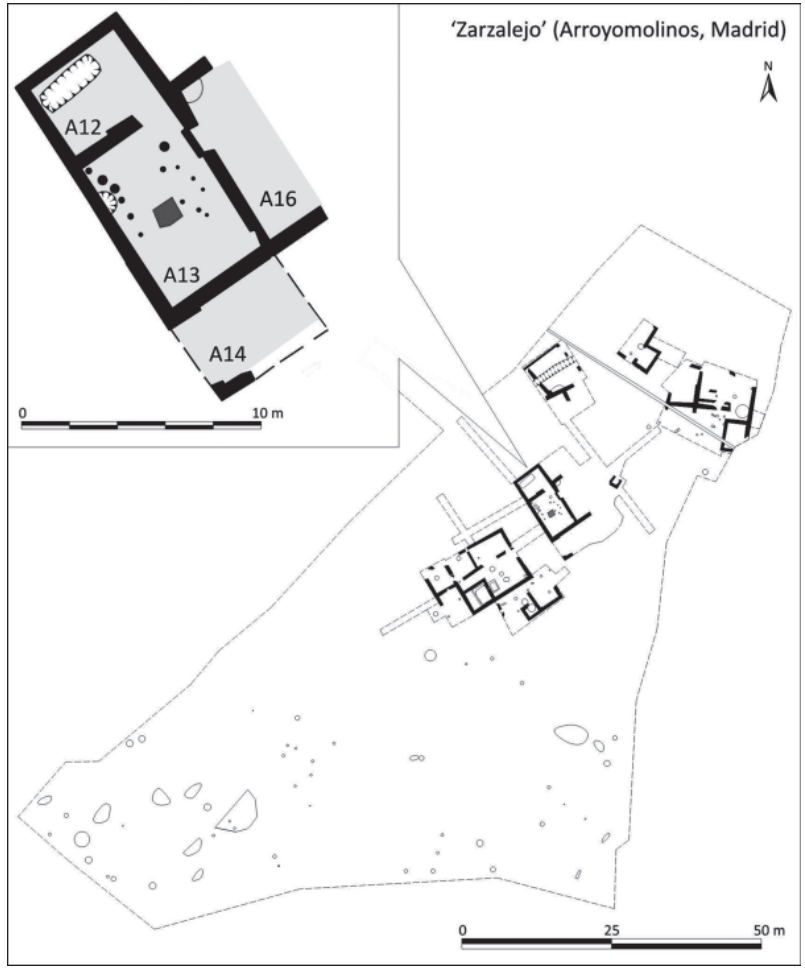

Fig. 3. Planta del área excavada y detalle de la vivienda con hogar en posición central (Zarzalejo)

ra 4). Una serie de pequeños agujeros de poste en torno al hogar tal vez tengan relación con el uso de la cocina; otras dos manchas de fuego de forma irregular (UUEE 1237, 1238) se documentan en el lado Este del mismo ambiente. La habitación presenta dos vanos, uno al Este da acceso al porche abierto al patio, el otro, al Norte, a una estancia menor que presenta en su suelo una fosa rectangular a modo de fresquera alineada con su pared septentrional.

\subsection{La casa bajoimperial de El Rasillo (distrito de Barajas, Madrid)}

El yacimiento de El Rasillo fue objeto de intervenciones arqueológicas entre los años 1999 y 2000 a resultas de su afección parcial por obras relacionadas con la ampliación del aeropuerto de Madrid-Barajas (Vigil-Escalera 2004, 2009b). Se localiza en la orilla occidental del río Jarama, en terrenos sedimentarios de vega, llanos, regables y de alta potencialidad agraria.

La vivienda que hemos seleccionado de El Rasillo forma parte de una serie de construcciones en torno a un gran espacio abierto, probablemente la parte rústica de un establecimiento tipo villa con su sector noble y sus termas al Este, sobre la playa fluvial. La casa en cuestión se data entre el último cuarto del siglo IV e inicios del siglo $\mathrm{V}$ d.C., momento en el que resulta abandonada dejando en su

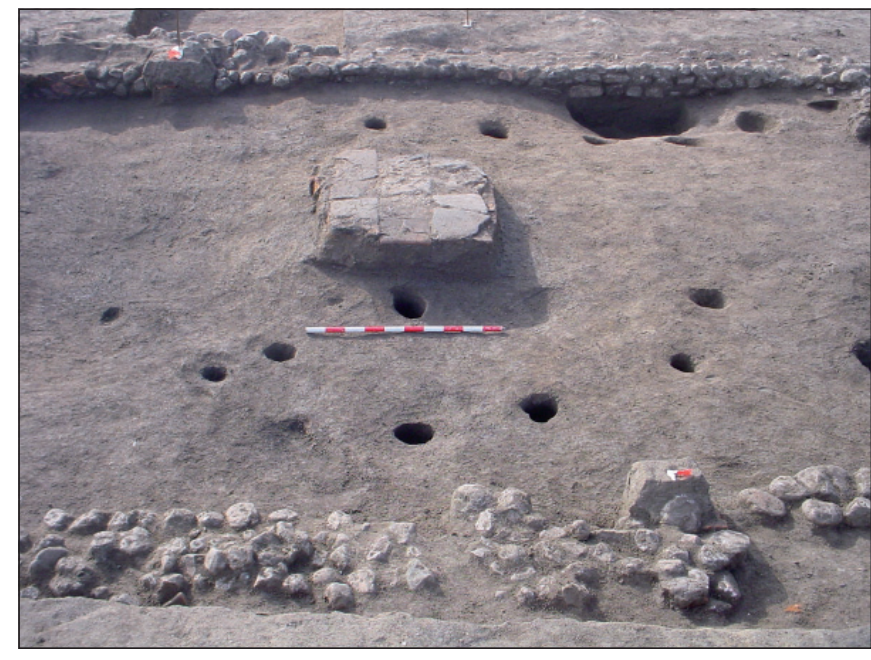

Fig. 4. Fotografía del hogar solado de ladrillos del ambiente A13 (Zarzalejo)

interior, dentro de una fosa, una ocultación de enseres domésticos (recipientes de cerámica y vidrio) y diversos objetos de hierro y bronce (Pozuelo, Vigil-Escalera 2003). La estancia principal (A8) es un ambiente de planta rectangular con un hogar construido con placa de ladrillos sobre poyete de adobe, adosado al centro de su pared occidental (Figura 5). Otros dos ambientes menores (A5 y A7) se adosan al anterior por el Oeste. El meridional presenta igualmente un hogar sobre una pequeña platafor-

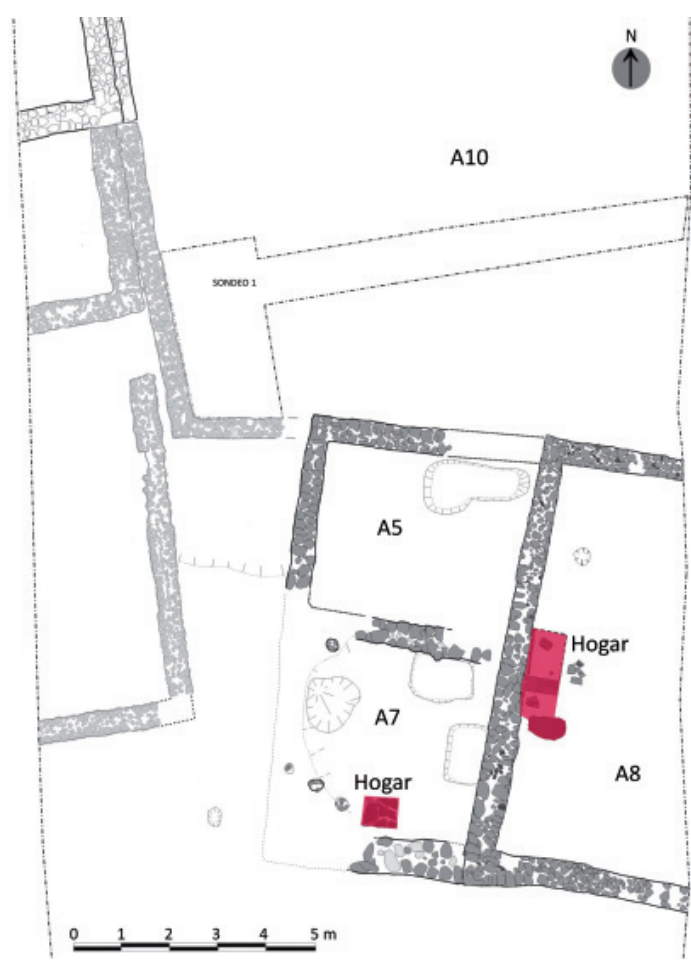

Fig. 5. Vivienda de época bajoimperial de El Rasillo (Barajas, Madrid) con señalización de los hogares 


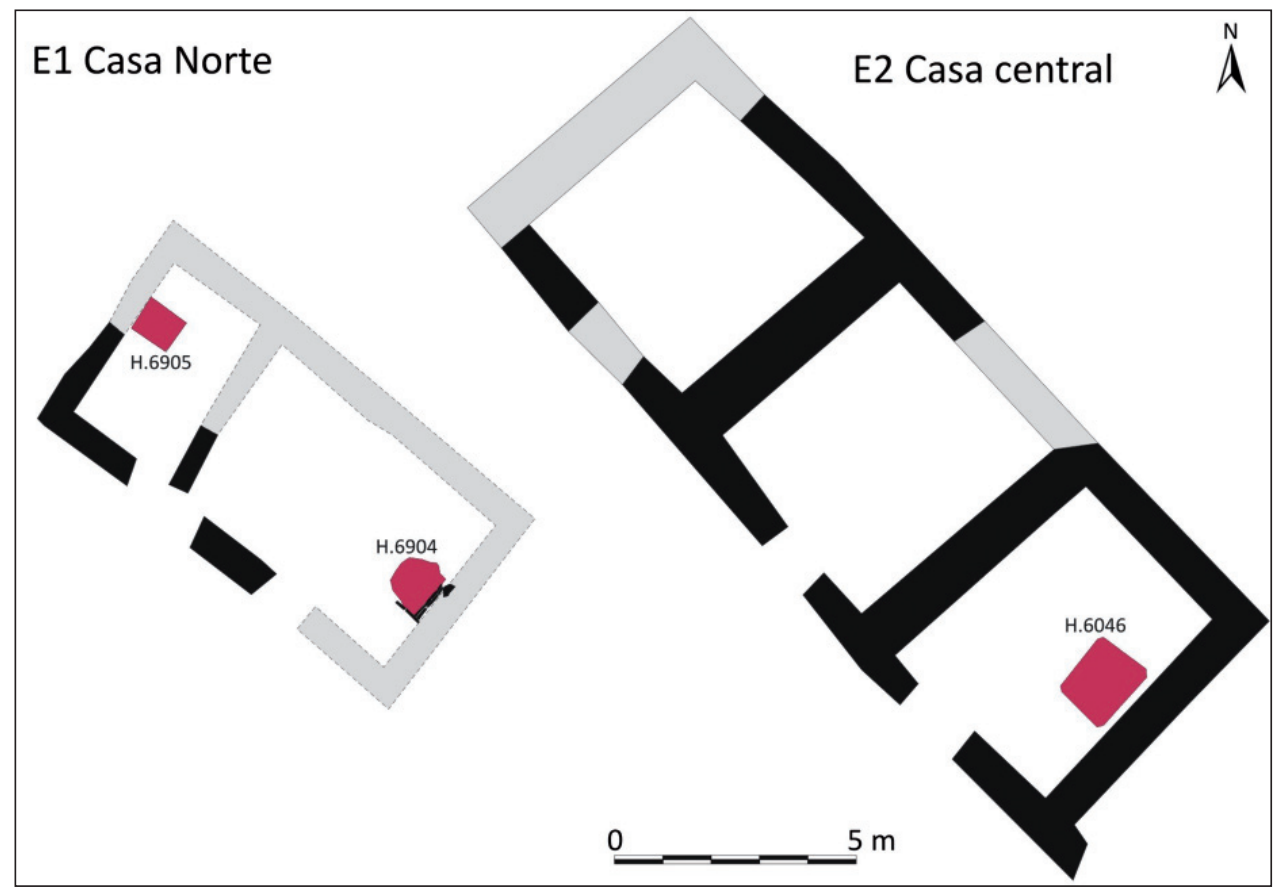

Fig. 6. Los edificios E1 y E2 de Congosto, con el emplazamiento de sus hogares

ma hecha a base de cantos rodados (UE 7119). Dadas las características de la secuencia de ocupación, puede estimarse que ambos hogares fueron utilizados contemporáneamente, tal vez con distinta funcionalidad o por parte de distintos individuos o grupos de la unidad doméstica.

En los establecimientos rurales de época romana de la región madrileña que hemos tenido ocasión de describir, pues, los hogares tienden a situarse sobre pequeños bancos ligeramente elevados sobre la cota de suelo. En algunos casos presentan soleras de ladrillo y suelen ubicarse en el centro de las habitaciones principales de la vivienda, tanto en posición exenta como adosados a uno de los muros largos. Son habituales, por otra parte, las huellas de rubefacción de planta circular en el centro de otras habitaciones, tal vez testimoniando la habilitación de sistemas de calefacción o alumbrado. En alguno de los sitios, determinados ambientes pueden desempeñar la función de cocina, y no se ha documentado con claridad la existencia de hornos abovedados para la cocción del pan.

\section{HOGARES Y HORNOS DOMÉSTICOS EN CONTEXTOS ALTOMEDIEVALES (SS. V-VIII d.C.)}

Llevaremos a cabo en este apartado una selectiva ilustración de casos de hogares y hornos documentados en asentamientos altomedievales de la región de Madrid para los que contamos con una documentación arqueológica suficientemente explícita. Se tratará de incidir en la variabilidad estructural o constructiva, en la cronología asigna- da a los contextos y en las relaciones espaciales de estas estructuras entre sí y con la vivienda, pretendiendo no un ensayo de sistematización, sino una primera aproximación a la entidad y significado de las mismas.

\subsection{Congosto (Rivas-Vaciamadrid)}

El yacimiento de Congosto, emplazado sobre la vega del río Manzanares, fue objeto de una exploración arqueológica en extensión debido a la afección provocada por un proyecto constructivo en el año 2004 (Martín, Rincón 2004). Los terrenos albergaban estructuras pertenecientes

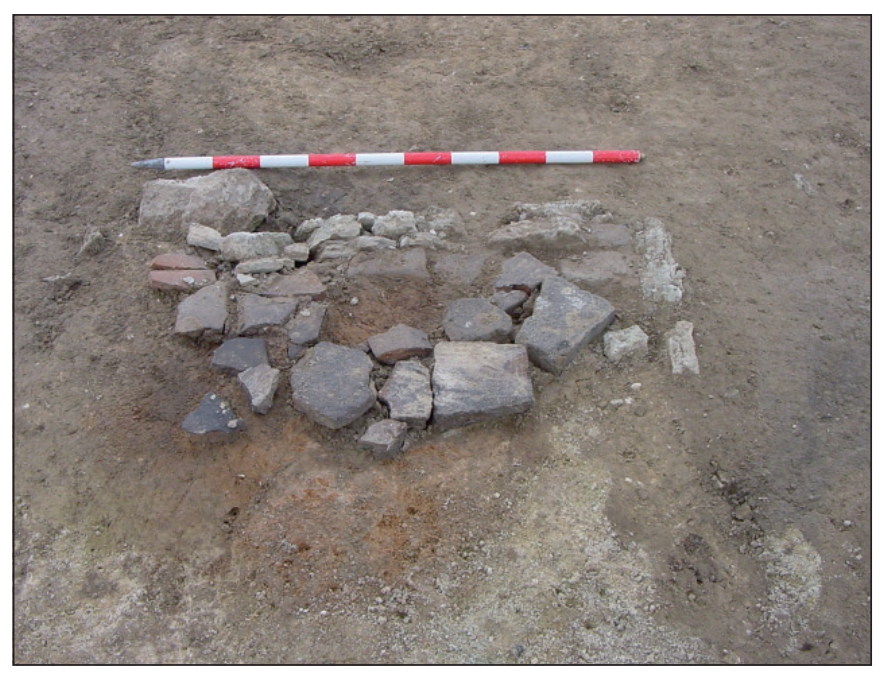

Fig. 7. Fotografía desde el NO de los restos conservados del hogar 6904, en el edificio $\mathrm{E} 1$ 


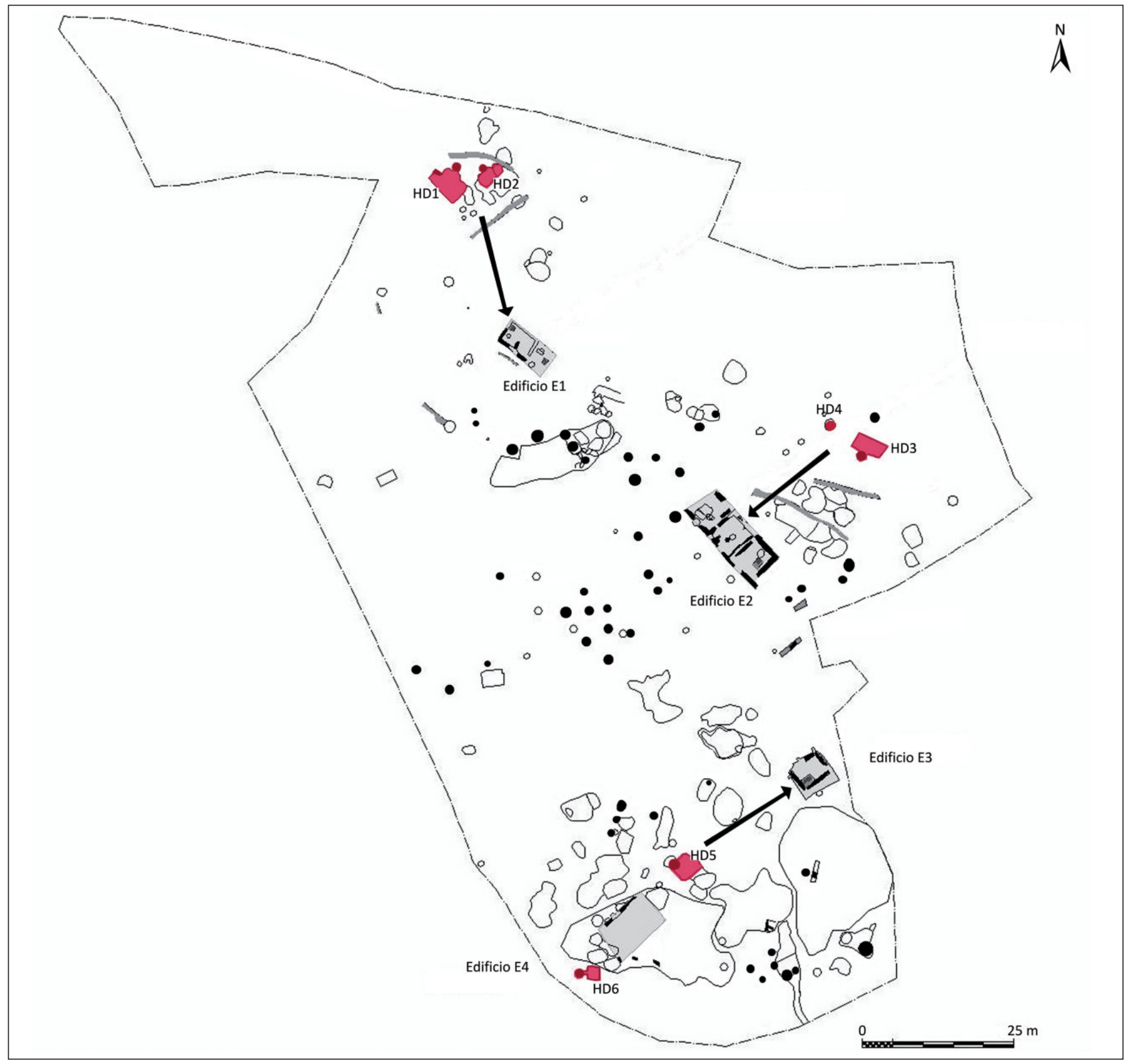

Fig. 8. Planta del periodo de ocupación altomedieval del yacimiento Congosto. Las flechas indican las asociaciones entre hornos domésticos (HD) y viviendas

a sucesivas ocupaciones prehistóricas y a un establecimiento altomedieval ocupado entre el último tercio del siglo $\mathrm{V}$ y el siglo VII d.C. El análisis del repertorio cerámico permitió definir una secuencia de evolución de la ocupación altomedieval marcado por un progresivo desplazamiento al Sur del núcleo de la actividad de solo una o dos unidades domésticas (Quirós, Vigil-Escalera 2006: 86-90, Fig. 6; Vigil-Escalera 2007a: 259).

Los edificios con zócalo de piedra de las fases más antiguas (E1 Norte y E2 central) presentaban estructuras de fuego en su interior (Figura 6). A pesar del extremada- mente precario estado de conservación de E1 (área 6900), se pudieron documentar dos hogares de planta cuadrangular (UUEE 6904 y 6905), delimitados por pequeñas lajas de yeso hincadas, con solera de fragmentos de material latericio y teja, ligeramente rehundidos respecto a la cota de frecuentación interior de los ambientes (Figura 7). La restitución completa en planta de este edificio y su división interna es hipotética. Las dimensiones de los hogares son de 100/110 cm de lado el mayor, del ambiente oriental, y $80 / 90 \mathrm{~cm}$ de lado el menor (occidental). En el edificio E2 se reconoce al menos un hogar construido, del mismo tipo 
que los anteriormente señalados (a ras de suelo, planta cuadrangular, delimitación mediante lajitas hincadas, solera de fragmentos de teja y ladrillo). La datación de estos edificios dentro del primer periodo de la secuencia de ocupación altomedieval establecida para el yacimiento implica unas fechas comprendidas entre el último cuarto del siglo $\mathrm{V}$ y el primer tercio del VI d.C.

A cierta distancia de cada uno de los edificios interpretados como viviendas (Figura 8), se emplazan algunas cabañas de perfil rehundido con hornos adosados, con soleras de fragmentos de teja, ladrillo o cerámica y huellas evidentes de rubefacción. Unos 22 metros al Norte de E1, por ejemplo, se localizan las cabañas con horno UUEE 670-680-690 y 650-660, en el extremo septentrional del perímetro parcelario marcado por una gran zanja curva. $\mathrm{Al}$ Este de E2, a unos 21 metros, se localizan la cabaña UE 2090 con horno adosado y el posible horno UE 1320. Unos 21 metros al Oeste de E3, el edificio meridional, encontramos de nuevo una cabaña con horno adosado (UE 4770-4774). En el extremo suroeste del área explorada, la pequeña cabaña de perfil rehundido UE 5650 con horno adosado constituye el único caso para el que resulta difícil establecer una asociación directa con alguna estructura residencial coetánea.

En este yacimiento, desde su implantación a finales del siglo $\mathrm{V}$ d.C., encontramos ya perfectamente configurada la que será una constante en la arquitectura doméstica de todos los asentamientos campesinos altomedievales de la región: la marcada diferenciación topográfica y previsiblemente funcional entre los hogares, situados en el interior de los espacios residenciales, de arquitectura bastante simple, y los hornos con cámara abovedada, ubicados siempre a cierta distancia de la vivienda principal.

\subsection{La casa de El Pelícano P01A (Arroyomolinos, Madrid)}

El yacimiento de El Pelícano ha sido parcialmente excavado en extensión de forma discontinua entre los años 2002 y 2010, según se iban ejecutando sucesivas promociones urbanísticas en la orilla Norte del arroyo de Los Combos. A lo largo de las casi siete hectáreas exploradas de la aldea altomedieval se documentaron restos arqueológicos correspondientes a ocupaciones durante distintos periodos, desde la prehistoria a la Baja Edad Media. Objeto de reseñas parciales en varias publicaciones ${ }^{5}$, aún resta pendiente su edición integral. El asentamiento altomedieval (ss. V-VIII d.C.) se desarrolla a partir de la transformación de un

${ }^{5}$ Vigil-Escalera 2009a, 2009c, con la bibliografía anterior.

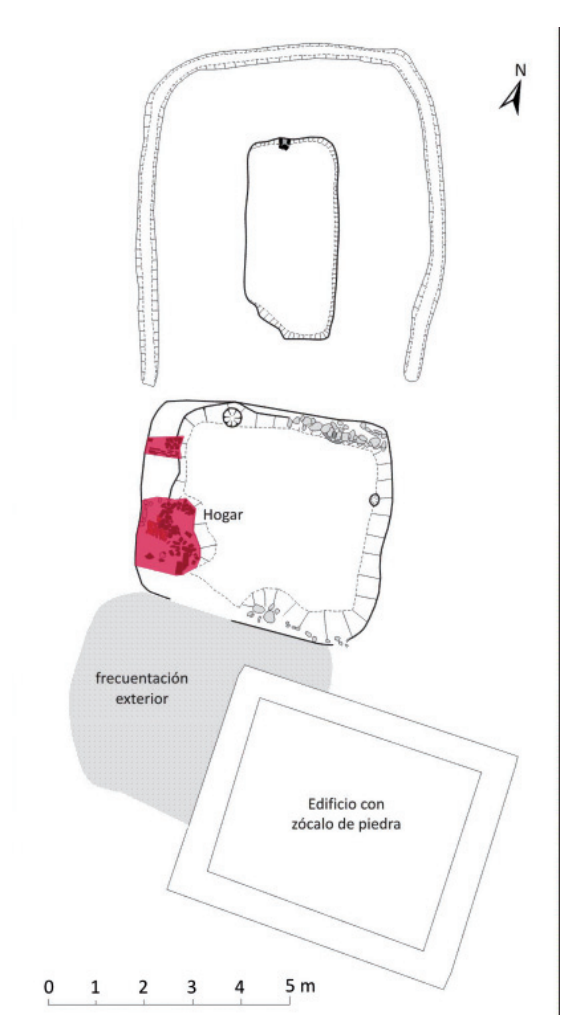

Fig. 9. Núcleo principal de estructuras de la unidad doméstica documentada en el sector P01A de EI Pelícano

establecimiento romano bajoimperial, localizado aguas abajo del arroyo, en el sector denominado P10 o El Jardín. El cementerio de la comunidad se emplaza a escasa distancia de aquellas ruinas, en torno a un mausoleo de la misma cronología. El hábitat permanece relativamente concentrado en un sector próximo a la necrópolis hasta la segunda mitad del siglo VI, cuando diversas unidades domésticas comienzan a instalarse aguas arriba ocupando una gran extensión de terreno.

En el caso de la unidad doméstica localizada en el sector P01A, datada en torno a mediados o la segunda mitad del siglo VI d.C., no fue identificada ninguna estructura con los rasgos propios de un horno en el entorno de la vivienda. El rasgo más destacable de esta unidad sería su articulación en tres módulos (Figura 9). El meridional, con zócalo perimetral de piedra, muy arrasado, podría interpretarse tal vez como un espacio de almacenamiento. El bloque Norte, separado en dos, tiene probable carácter residencial y presenta un espacio presumiblemente de alcoba en la parte trasera (delimitado por una roza simple en el terreno, de planta rematada en curva, con una fosa menor rectangular centrada en su interior) y un ambiente principal de perfil rehundido con restos identificables de hogar solado con fragmentos cerámicos y peque- 
ños mampuestos de piedra en su lado occidental, a la izquierda del acceso. La definición arqueológica del hogar es imprecisa, dado el precario estado de conservación de sus restos. La solera se dispone sobre un banco o resalte unos $10-15 \mathrm{~cm}$ por encima de la cota de suelo interna del ambiente semisubterráneo. A unos escasos metros al Sur del conjunto se disponen cuatro silos y un probable pozo.

\subsection{La Huelga (Barajas, Madrid)}

La exploración arqueológica en el yacimiento de La Huelga, en terrenos situados a orillas del río Jarama, estuvo motivada por la excavación de una gran trinchera para el soterramiento de una infraestructura de transporte de electricidad en el año 2000 (Domínguez et al. 2004). Como en el caso del antes citado caso de El Rasillo, del asentamiento altomedieval sólo conocemos pues los resultados de la intervención sobre un largo corredor de 15-18 metros de ancho. En el sector meridional de la intervención se identificaron un grupo de silos, pozos, zanjas, dos cabañas de perfil rehundido y planta rectangular y una inhumación aislada.

Los únicos testimonios relativos a estructuras domésticas de combustión consisten en un horno de bóveda presumiblemente hemisférica adosado a la cabaña de perfil rehundido UE 7003-7068 en el extremo Oeste de su lado largo septentrional (Figuras 10-11). Se conservan la parte de la solera del horno excavada en el sustrato geológico y apenas unos $12 \mathrm{~cm}$ de las paredes inferiores de la bóveda. La solera, de arcilla rubefactada y unos $3 \mathrm{~cm}$ de espesor, presenta un diámetro de entre 142 y $147 \mathrm{~cm}$. La zona de la embocadura del horno se construyó sobre estratos de amortización de la primera fase de uso de la cabaña, sirviéndose para su construcción de pequeños mampuestos de piedra (cantos rodados) y fragmentos de material latericio.

En este caso resulta meridianamente claro que la instalación del horno constituye un añadido realizado a una cabaña de perfil rehundido y planta subrectangular

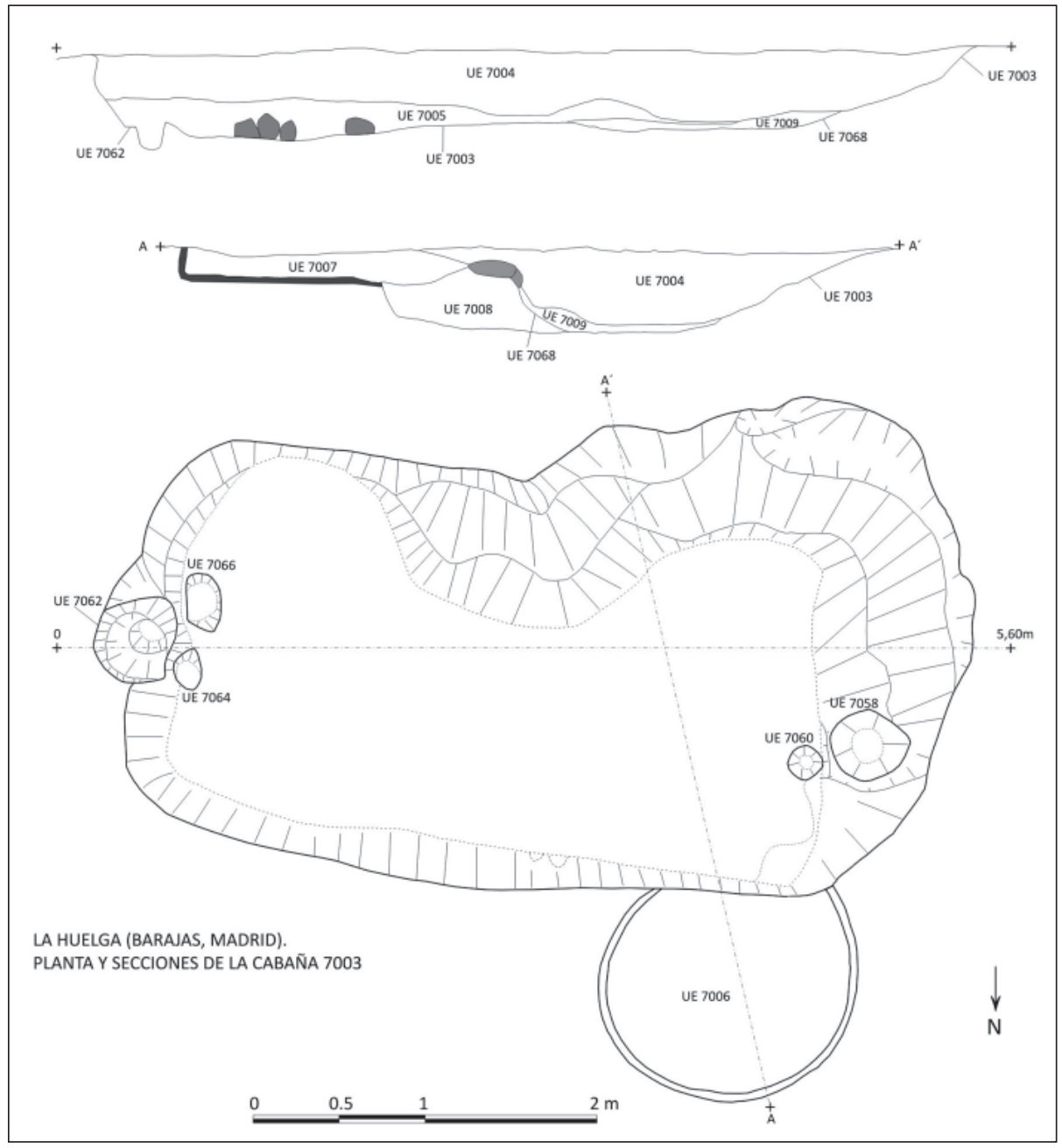

Fig. 10. Planta y secciones de la cabaña con horno UE 7003-7068 (La Huelga, Madrid) 


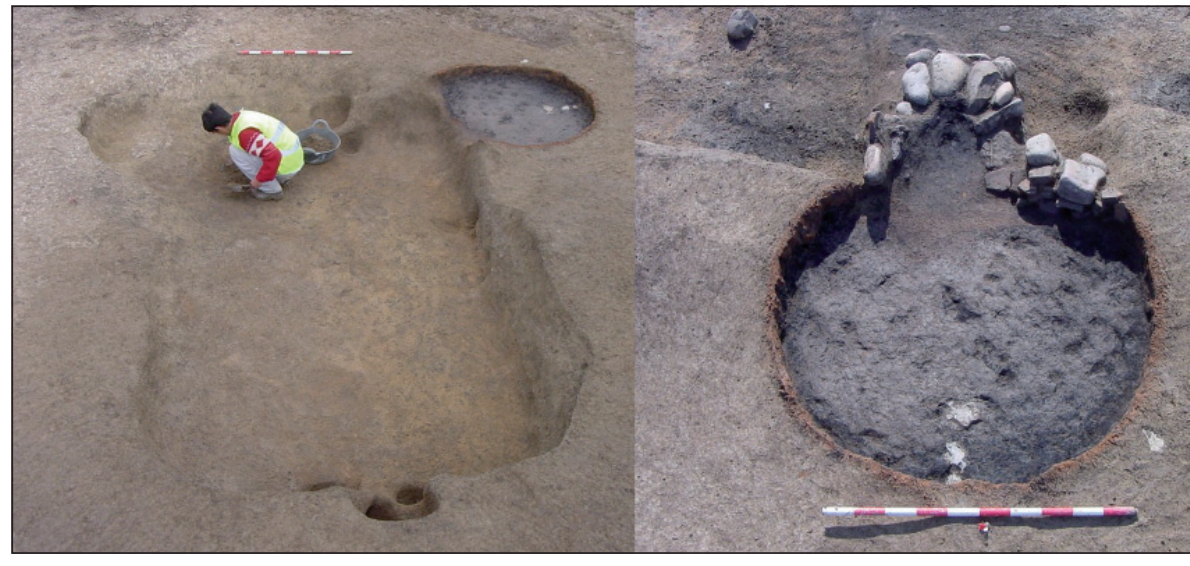

Fig. 11. Fotografía final y detalle de la estructura del horno (La Huelga, Madrid) preexistente que se encontraba ya entonces parcialmente amortizada. Aunque es difícil proceder a estimar el posible lapso transcurrido entre ambos usos, e incluso si existió una fase de inactividad entre ellos, los repertorios cerámicos proporcionados por los distintos estratos de relleno de la estructura y sus dos fases de amortización resultan a la

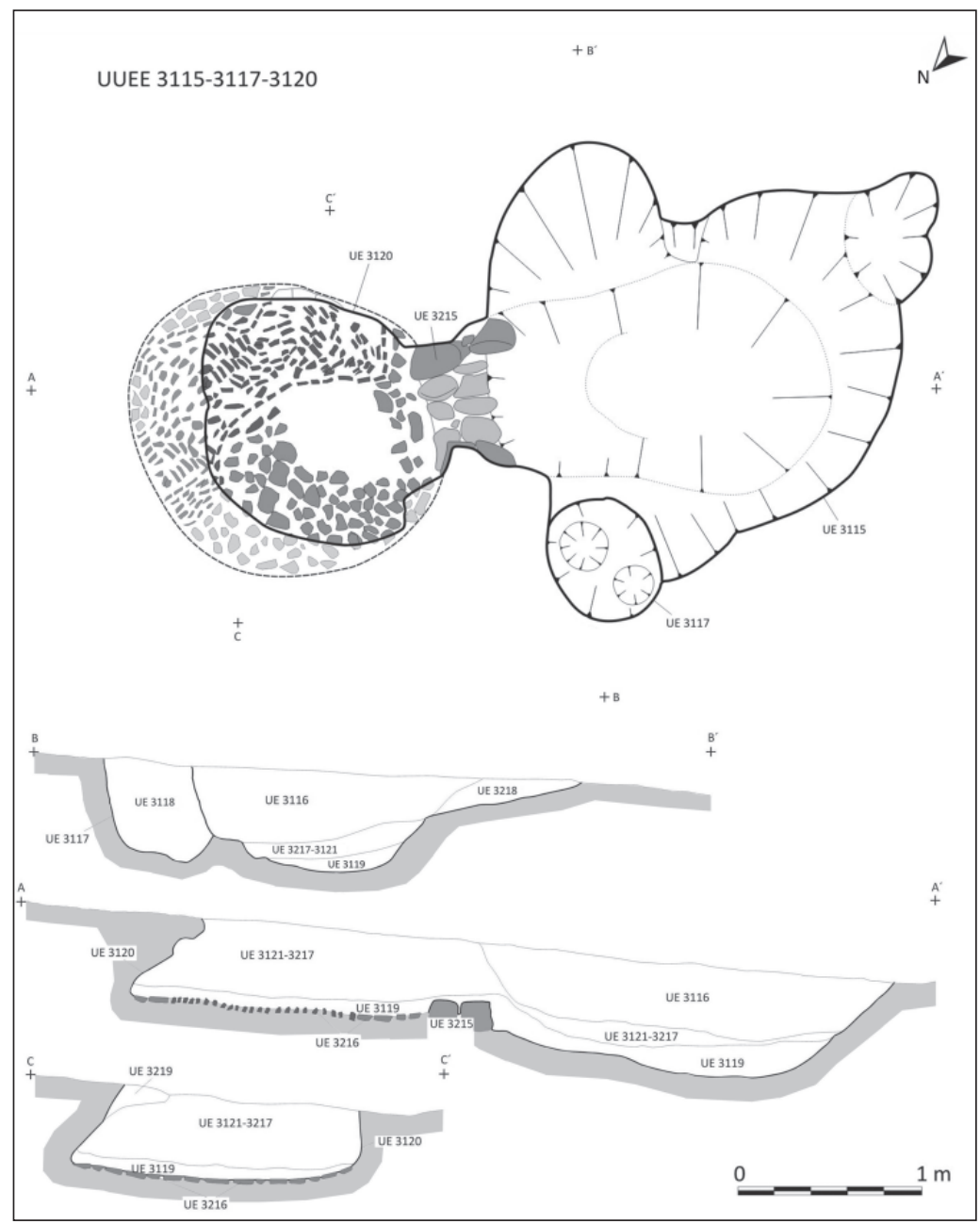

Fig. 12. Planta del horno exento UE 3115, en el sector P02 de El Pelícano postre muy homogéneos, y su análisis ${ }^{6}$ determinaría que la cabaña estuvo probablemente en funcionamiento entre el último cuarto o finales del siglo $\mathrm{V}$ y el primer cuarto del siglo VI d.C.

\subsection{Los hornos del sector PO2 de EI Pelícano}

En el sector P02 del ya citado yacimiento de El Pelícano, a unos 300 metros al Oeste del sector P01A, se documentaron al menos cuatro grandes conjuntos de estructuras que podrían asociarse a otras tantas unidades domésticas. En el más occidental no se reconoció con claridad el emplazamiento de la vivienda, pero sí dos estructuras independientes asociadas a funciones culinarias cuya descripción en detalle se expone a continuación.

El horno exento UE 3115-3117-3120 presenta un aceptable estado de conservación (Figura 12). Se identifican una cámara de cocción abovedada con solera acondicionada con fragmentos de teja y su embocadura construida con grandes bloques de piedra. El espacio de trabajo delante del horno presenta sendos rebajes laterales y las huellas de lo que pudieron ser algunos de los elementos sustentantes de su cubierta (postes de madera).

La disposición de los fragmentos de material latericio en la solera de la cámara (una parte puesta de canto, otra en plano, se advierte una línea sinuosa de trozos de teja dispuestos verti-

${ }^{6}$ Altos porcentajes de cerámica depurada de mesa (cuencos y jarros) y muy escasa representación de las producciones modeladas (menos del 5\%). El repertorio presenta una fuerte residualidad de materiales de época altoimperial romana, casi un $25 \%$ del total de fragmentos. 
Fig. 13. Planta y sección de la cabaña con horno UE 3210, en el sector P02 de El Pelícano. En sombreado más oscuro, la probable disposición de los postes durante su segunda fase

\section{El Pelícano P.L2}

UE 3210

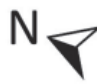

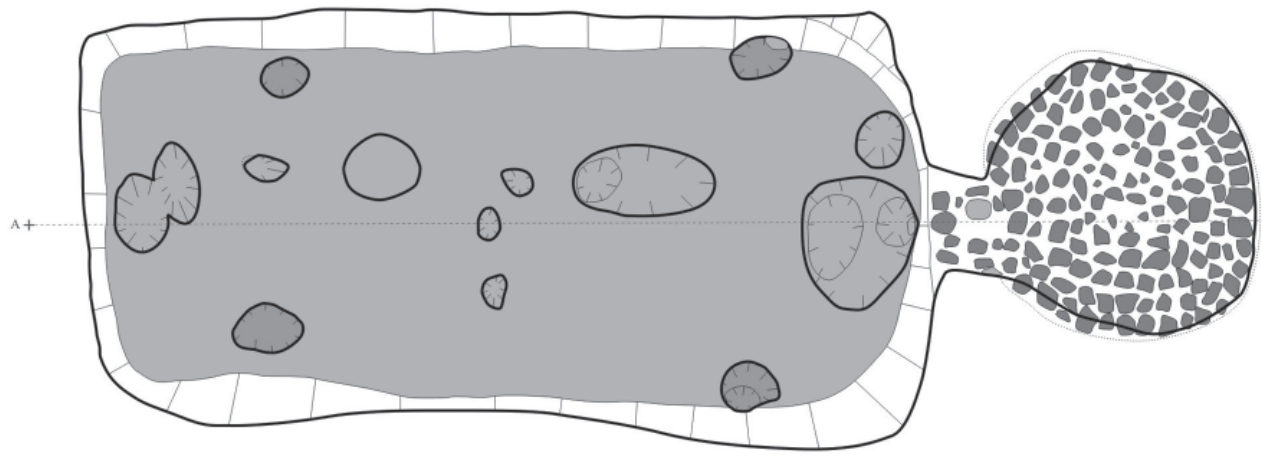
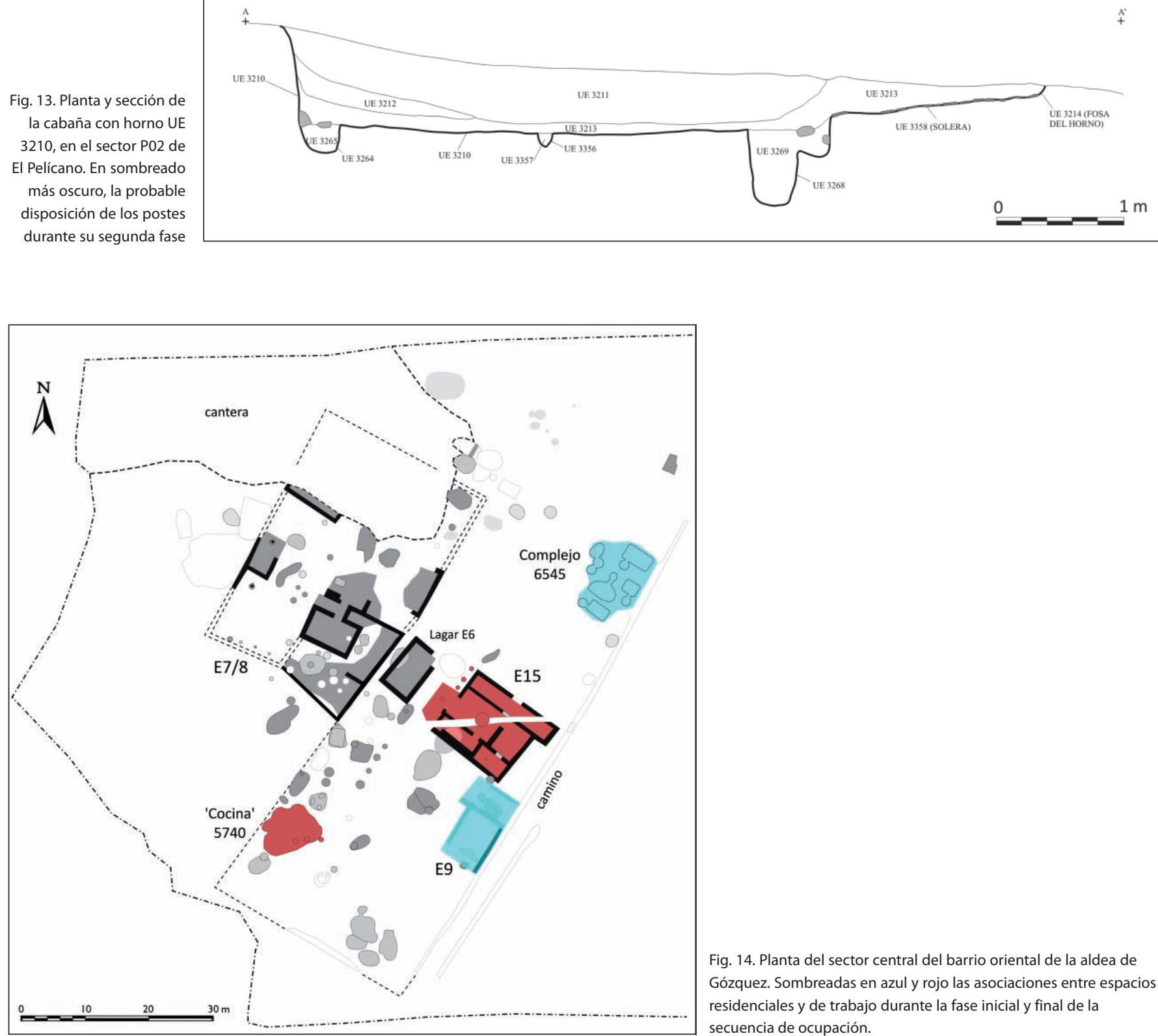

Fig. 14. Planta del sector central del barrio oriental de la aldea de Gózquez. Sombreadas en azul y rojo las asociaciones entre espacios residenciales y de trabajo durante la fase inicial y final de la secuencia de ocupación. 
calmente) sugiere la posibilidad de que ésta fuera remodelada o reparada en distintas ocasiones. Su diámetro ronda los $160 \mathrm{~cm}$, y la boca tiene una anchura mínima de $32 \mathrm{~cm}$. La amortización de la estructura, de acuerdo al repertorio cerámico, podría datarse durante el primer tercio del VIII d.C.

La cabaña con horno adosado UE 3210 parece haber sido acondicionada como tahona en un segundo momento, o al menos eso podría deducirse de la reordenación de los apoyos de sustentación de su cubierta conservados en su interior (Figura 13). La solera del horno, acondicionada con fragmentos de teja, presenta pendiente hacia la embocadura. Tiene un diámetro aproximado de entre 140-150 $\mathrm{cm}$., y la anchura mínima de su boca es de $46 \mathrm{~cm}$. Los estratos de oclusión que amortizan definitivamente la estructura proporcionaron un lote de restos cerámicos fechable a grandes rasgos durante la primera mitad del siglo VII d.C.

\subsection{Los conjuntos asociados de viviendas y hornos de Gózquez (San Martín de la Vega, Madrid)}

La aldea altomedieval de Gózquez fue excavada entre los años 1997 y 2000 a consecuencia de la implantación de un parque de ocio. Los trabajos desarrollados revelaron la extensión en planta del asentamiento (unas 12 hectáreas), con su necrópolis comunitaria en el centro, dividiendo el poblado en dos barrios. El oriental fue objeto de una excavación intensiva que permitió reconocer una estructura parcelaria rígida en la que alternaban sectores vacíos (parcelas de uso agrario) y otras intensivamente ocupadas por estructuras sucesivamente amortizadas entre el segundo cuarto del siglo VI y mediados del VIII d.C. (VigilEscalera 2007a, 2009a).

Cada unidad parcelaria de uso residencial-auxiliar parece haber contado con un edificio principal en torno al cual se distribuyen aisladas o en racimos distintas clases de

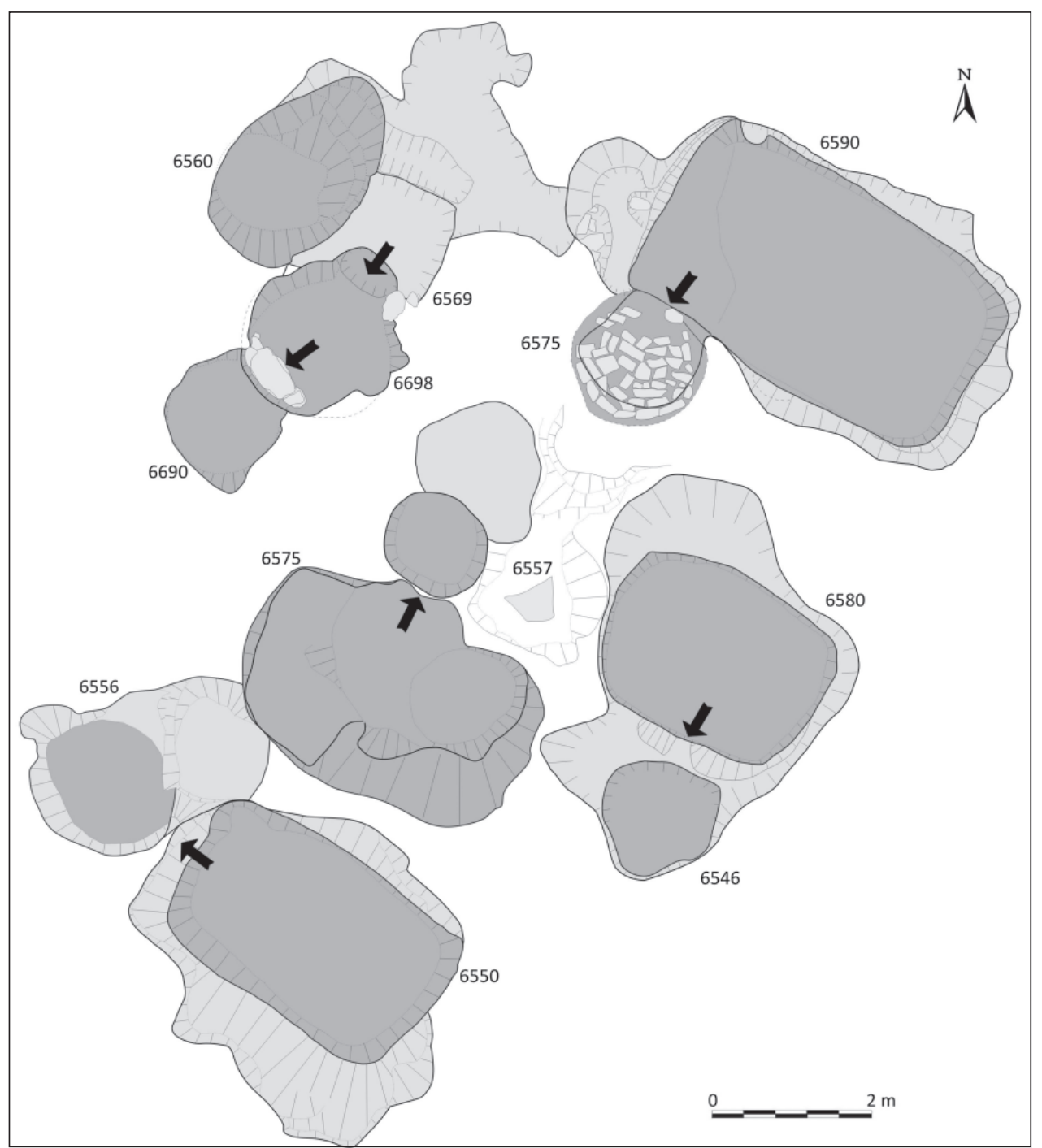

Fig. 15. Complejo 6545, de horno exento y cuatro cabañas con horno, de Gózquez (S. Martín de la Vega, Madrid) 
Fig. 16. Conjunto de estructuras interpretado como cocina o tahona (UE 5740), en la que se reconocen el uso sucesivo de al menos tres hornos domésticos. Sector central del barrio oriental de la aldea de Gózquez

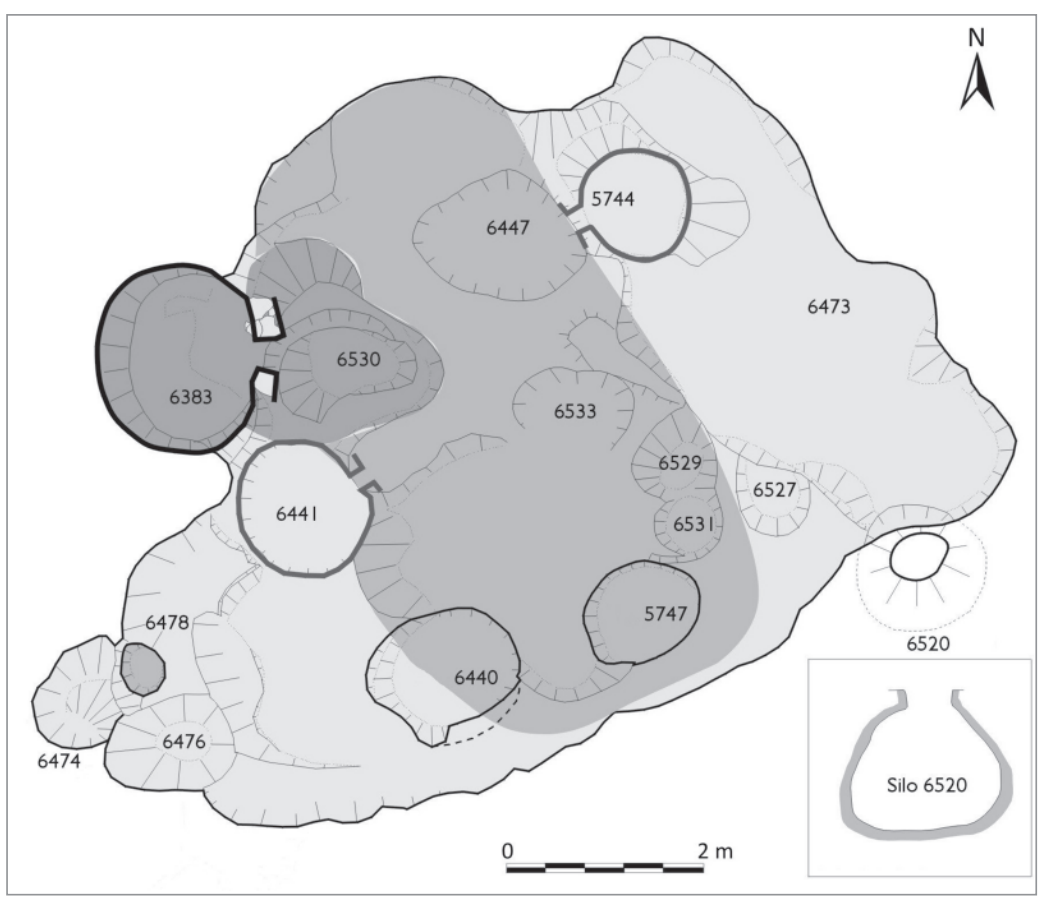

estructuras auxiliares: silos, cabañas de perfil rehundido, algún pozo... La reutilización de material constructivo (mampostería de piedra y teja) es insidiosa, de modo que los vestigios de las primeras fases de ocupación que no son fosas casi han desaparecido por completo. En el sector central (Figura 14) se intuye el emplazamiento de ese edificio nuclear (E9) durante las primeras fases de ocupación alineado con las zanjas que delimitan un camino que separa esta parcela de la contigua, presumiblemente cultivada. El conjunto de cabañas con hornos adosados y de hornos exentos denominado complejo 6545 (Figura 15) debe ser coetáneo a la actividad de ese edificio, del que queda separado unos 40 metros, siempre flanqueando la estructura viaria citada.

Durante las dos últimas fases de ocupación (segunda mitad del siglo VII y primera del VIII d.C.) el núcleo de esa parcela central la conforma el edificio E15, con su lagar E6 al Oeste. Los hornos correspondientes a este periodo se concentran en la estructura denominada UE 5740, donde se advierten las huellas de al menos tres estructuras de cocción (Figura 16). La última de ellas en activo (UE 6383) fue abandonada con la última carga de combustible en su interior, formada por ramas o plantas leñosas con un diámetro no superior a los 2-3 cm. Los hornos documentados presentan todos ellos distintas dimensiones, pero parece que fueron aparejados de forma relativamente similar, con la embocadura construida con fragmentos de teja dispuestos verticalmente. En ningu- na de las cámaras se utilizaron soleras de fragmentos cerámicos.

Complejos con hornos aparentemente yuxtapuestas de similar funcionalidad, como el de la 'cocina' 5740 de Gózquez, tienen paralelos muy estrechos en una estructura datada en época carolingia de Villiers-le-Sec (Gentili 1999, citado en Bruley-Chalbot 2007) o en otra de la segunda mitad del siglo VI de la Plaça Major de Castellar del Valles, en Barcelona (Roig 2009: 235-7, Fig. 4). En todos los casos, la yuxtaposición sería solo aparente, resultado de la sucesiva construcción y reemplazo de unos hornos por otros dentro del mismo ámbito construido de sentido unitario.

Otra estructura doméstica de combustión de interés documentada en el yacimiento sería la cabaña de suelo rehundido UE 5200 con horno adosado (VigilEscalera 2007c: Fig. 4). Dado su emplazamiento, debería estar relacionada con la actividad de los edificios E2E3, de los que dista unos 20 metros al Sureste. Destacamos la singularidad de esta estructura porque, dadas sus reducidas dimensiones, podría excluirse para la misma una función diversa de la específicamente relacionada con la cocción, fuera o no concebida originalmente con ese propósito ${ }^{7}$.

\footnotetext{
7 No puede excluirse del todo que la fosa original de la cabaña de perfil rehundido careciese del horno, y que éste le fuera adosado en un momento posterior. Se conoce alguna estructura de similar formato en el mismo yacimiento en la que no se ha reconocido ningún elemento adicional al margen de la propia fosa subrectangular.
} 


\section{RECAPITULACIÓN}

El somero análisis efectuado sobre las estructuras domésticas de combustión (hogares y hornos) documentadas en varios yacimientos rurales del periodo altomedieval en el centro de la Península Ibérica nos lleva a delinear algunas conclusiones, por fuerza provisionales.

En primer lugar, la investigación sobre este tipo de estructuras en nuestro país (pero no solo) se encuentra en un estadio relativamente incipiente. Los análisis llevados a cabo sobre esta clase de estructuras al otro lado de los Pirineos (Bruley-Chalbot 2007) han permitido fijar algunos de los parámetros que deberían guiar su sistematización formal. De igual forma, los casos estudiados en Francia revelan una paulatina transformación de los hornos hacia tipos de mayores dimensiones y con periodos más prolongados de actividad, lo que viene a coincidir con la progresiva implantación a partir del siglo $\mathrm{x}$ del uso comunal o colectivo en detrimento del carácter familiar que tienen las estructuras altomedievales más antiguas.

En segundo lugar, parece relativamente complejo en bastantes casos, sobre todo a causa del estado de deterioro de la cota de frecuentación original de los yacimientos, discriminar entre las estructuras utilizadas sencillamente como hogar y las que fueron hornos. Las primeras (hogares) parecen emplazarse por norma en el interior de la vivienda, sin que sea posible determinar comportamientos sistemáticos ni pautas constructivas complejas. Frente a los hogares construidos sobre plataforma que caracterizan el periodo romano, los altomedievales suelen yacer directamente sobre la cota de uso del ambiente. Las segundas (hornos) suelen localizarse a cierta distancia del espacio residencial principal, entreviéndose en ello una conducta deliberada. No se tiene constancia, hasta el momento, de la documentación de hornos domésticos en los asentamientos de época romana imperial en la región. El modelo arquitectónico de horno repetido en los sitios de cronología altomedieval podría entenderse, a priori, como un elemento innovador en la arquitectura doméstica de esta etapa, con estrechos paralelos en otras partes de la propia península Ibérica o del continente europeo ${ }^{8}$.

Por lo que respecta a las variables morfológicas observadas en el elenco de sitios abordado podrían deslindarse dos grandes grupos de estructuras para el horneado, independientemente de que todas ellas han debido contar con alguna clase de cubierta techada: los hornos exentos, en los que el área de manipulación es reducida y el edificio que lo engloba y su cubierta son apenas discerni-

${ }^{8}$ Vide supra, apartado 3.5. bles; y los hornos asociados a una cabaña de suelo rehundido, en cuyo caso la protección del horno frente a la intemperie es compartida con la de la estructura en la que se aloja. Los casos conocidos nos revelan que la cabaña de suelo rehundido puede ser construida específicamente para albergar un horno (como en el caso de las cuatro que integran el conjunto 6545 de Gózquez) o puede reutilizarse para ese específico propósito en un segundo momento, tanto presentando un aceptable estado de conservación (caso de la cabaña 3210 de El Pelícano P02) como habiendo sido parcial o completamente amortizada antes (cabaña 7003-7068 de La Huelga). Sería lógico pensar que las labores de amasado del pan, por ejemplo, tuvieran lugar en las citadas cabañas ${ }^{9}$, mientras que sería necesario proceder a esas mismas tareas en otra ubicación en el caso de operar con hornos exentos. No se excluye que una eventual alternancia en el uso de ambas estructuras pueda haber revestido un carácter estacional, dado que los asentamientos excavados en extensión demuestran que puede aparecer indistintamente más de un tipo de horno en el mismo yacimiento o incluso en el ámbito de una misma unidad doméstica.

La utilización de los hornos presenta una variada gama de alternativas (culinarias y extraculinarias) que en gran parte nos es desconocida. Es posible que la cocción del pan fuese en realidad un acontecimiento llevado a cabo con una regularidad temporal establecida, es decir, no simplemente una tarea diaria, lo que economizaría el esfuerzo empleado en la tarea y el gasto de combustible ${ }^{10}$. La relativa complejidad de la estructura, tanto la del propio horno como la del edificio en el que se alojaba, viene a sumarse a la elección para estas instalaciones de unos emplazamientos bastante estables. La recurrencia en el uso de los hornos parece demostrada, pero también las reformas, reconstrucciones o la nueva construcción de hornos en las inmediaciones de los preexistentes, muchas veces reutilizando las fosas abiertas con anterioridad. Una parte sustancial de los hornos que conforman el repertorio de ejemplos del centro peninsular se instalan aprovechando cabañas de suelo rehundido que funcionarían en realidad a modo de tahonas, con una función claramente subsidiaria con respecto a la vivienda principal. En algunos casos, dadas las escasas dimensiones del ambiente interior, podría

\footnotetext{
9 Utilizando para ello artesas de madera o incluso lebrillos (Gutiérrez Lloret 1991: 162-3). En este trabajo se cita un texto andalusí de finales del siglo XII donde se describen al menos cuatro formas distintas de cocer el pan.

${ }^{10} \mathrm{El}$ amasado y la cocción de pan con una periodicidad semanal, por ejemplo, aparece en la gestión de hornos de uso colectivo hasta época muy reciente (Albir 2010: 153-4)
} 
descartarse que tales cabañas hayan podido tener otro uso distinto del proceso de horneado.

Cuando hace algunos años se discutió acerca de la posible función residencial de las cabañas de suelo rehundido (Vigil-Escalera 2000), se señaló que la presencia de hornos y hogares podía ser una prueba al respecto ${ }^{11}$. Con arreglo a los datos ahora presentados, tal vez sea necesario matizar aquel supuesto. Los hornos adosados no constituirían en sentido estricto un testimonio directo sobre el uso residencial de determinadas cabañas, aunque sí determinan el ejercicio de determinadas tareas en su interior. El catálogo de yacimientos del centro peninsular ofrece, por otra parte, muy escasos ejemplos de hogares instalados en su interior (se registra un solo caso en Gózquez, otro posible en el sitio de Los Berrocales, en Vicálvaro, Madrid), aunque es cierto que el reconocimiento arqueológico de los poco consistentes vestigios de un hogar es problemático.

El carácter privado de la utilización de estos hornos altomedievales parece la alternativa interpretativa más plausible en función de las evidencias a nuestro alcance, lo que resulta compatible con los rasgos organizativos característicos de estos asentamientos y su división en unidades domésticas relativamente independientes en su agenda cotidiana. Es bastante probable que sólo funcionase un horno por unidad doméstica al mismo tiempo, independientemente del tamaño o número de individuos que la integraban ${ }^{12}$. La confirmación de este extremo puede resultar muy útil a la hora de esclarecer el número de unidades domésticas que componían un determinado asentamiento, aunque sigue y seguirá siendo complejo establecer la secuencia de sustitución de las estructuras singulares en activo.

\section{Bibliografía}

Alba Calzado M. 1997, «Sobre el ámbito doméstico de época visigoda en Mérida», Mérida. Excavaciones Arqueológicas 1997. Mérida, pp. 387-418.

Alba Calzado M., Gutiérrez Lloret S. 2008, «Las producciones de transición al mundo islámico: el problema de la cerámica paleoandalusí (siglos VIII y IX)», en D. Bernal Casasola, A. Ribera Lacomba (eds.), Cerámicas hispanorromanas. Un estado de la cuestión. Cádiz: Universidad de Cádiz, pp. 585-613.

Albir Herrero C. 2010, «Etnoarqueología de la elaboración del pan», Saguntum Extra 9, pp. 151-60.

Azkarate A., Quirós J.A. 2001, «Arquitectura doméstica altomedieval en la península Ibérica», Archeologia Medievale XXVIII, pp. 25-60.

Bazzana A. 1996, «Foyers et fours domestiques dans l'architecture rurale d'alAndalus", Arqueologia Medieval 4. Campo Arqueológico de Mértola. Lisboa, pp. $139-63$.

${ }^{11}$ Una excelente sistematización arqueológica de esta clase de estructuras en Tipper (2004).

${ }^{12}$ La deducción de un eventual uso comunitario de los hornos basada en el número de éstos por yacimiento y su emplazamiento, como sugiere Peytremann (2003: 294) puede resultar arriesgada.
Bruley-Chabot G. 1997, Les fours culinaires du haut Moyen Age en Ile-de-France, Mémoire de maîtrise, Université de Paris I, Sorbonne, multigraphié, dir. L. Pressouyre.

Bruley-Chabot G. 2000, «Les fours», en P.-J. Trombetta, M. Depraetere-Dargery (eds.), L'tle-de-France médiévale, t. 1: La vie de tous les jours, Drôle de Moyen Age, Du producteur au consommateur, Paris: Somogy, pp. 37-38.

Bruley-Chabot G., 2003, «Les fours culinaires en Ile-de-France», dans L'habitat rural du haut Moyen Age en Ile-de-France, PCR bilan 2002/2003, $1^{\mathrm{er}}$ suppl. au Bulletin archéologique du Vexin français, Guiry-en-Vexin (2003), pp. 25-31.

Bruley-Chabot G. 2007, "Fours et foyers culinaires du Haut Moyen Âge», $4^{\text {th }}$ International Congress of Medieval and Modern Archaeology (Paris, 3-8 september 2007). http://medieval-europe-paris-2007.univ-paris1.fr/G.BruleyChabot\%20texte.pdf (último acceso 25 junio 2012)

Caballero L., Mateos P., Retuerce M. (eds.) 2003, Cerámicas tardorromanas y altomedievales en la Peninsula Ibérica. Ruptura y continuidad (II Simposio de Arqueología. Mérida, 2001), Anejos de Archivo Español de Arqueología, XXVIII. Madrid, CSIC.

Cañavate Castejón V. 2008, Estructuras domésticas de época altomedieval en el Sureste peninsular: el Tolmo de Minateda (Hellin, Albacete), Albacete: Instituto de Estudios Albacetenses «Don Juan Manuel».

Domínguez Alonso R.M., Rincón Vázquez J., Vigil-Escalera Guirado A. 2004, Memoria de las excavaciones arqueológicas en el yacimiento "La Huelga", afectado por el soterramiento de línea eléctrica $400 \mathrm{Kv}$. (Barajas, Madrid). ÁREA, S.C.M. Memoria inédita, depositada en la DGPH de la Comunidad de Madrid.

Escalona Monge J. 2009, «The early Castilian peasantry: an archaeological turn?», Journal of Medieval Iberian Studies, 1 (2), pp. 119-45.

Gentili F. 2000, "Villages, maisons et annexes autour de l'an mil», en P.-J. Trombetta, M. Depraetere-Dargery (eds.), L'Ile-de-France médiévale, t. 1: La vie de tous les jours, Drôle de Moyen Age, Du producteur au consommateur, Paris: Somogy, pp. 28-37.

Gutiérrez Lloret S. 1990-91, «Panes, hogazas y fogones portátiles. Dos formas cerámicas destinadas a la cocción del pan en al-Andalus: el hornillo (tannur) y el plato (tabag)", Lucentum 9-19, pp. 161-75.

Gutiérrez Lloret S. 2000, «El espacio doméstico altomedieval del Tolmo de Minateda (Hellín, Albacete), entre el ámbito urbano y el rural», Castrum 6, Maisons et espaces domestiques dans le monde Mediterranéen au Moyen Âge, Roma-Madrid, pp. 151-64.

Hernández Hernández L., Hernanz P., Vigil-Escalera A. 2004, Memoria de las excavaciones arqueológicas en el yacimiento 'Zarzalejo' (Arroyomolinos, Madrid). 2003-2004. Memoria inédita, ÁREA, Soc. Coop. Mad. Depositada en la DGPH de la Comunidad de Madrid.

Martín Bañón A., Rincón Vázquez J. 2004, «Informe previo de la excavación en el yacimiento Congosto. Área de ampliación de la Escuela Nacional de Protección Civil (Rivas-Vaciamadrid, Madrid). Área, S.C.M. Informe inédito, depositado en la DGPH de la Comunidad de Madrid.

Morín J., Penedo E., Oñate P., Oreja G., Ramírez M., Sanguino J. 2007, «La necrópolis hispanovisigoda de La Indiana (Pinto, Madrid)", Zona Arqueológica 8, Vol. II, pp. 566-579.

Peytremann E. 2003, Archéologie de l'habitat rural dans le nord de la France du VI au XII siecle, Tomo XIII des Mèmoires publiés par l'Association française d'Archéologie mérovingienne, Saint-Germain-en-Laye, 2 vols.

Pozuelo Lorenzo D., Vigil-Escalera A. 2003, "La ocultación de un ajuar doméstico a inicios del siglo V d.C. en El Rasillo (Barajas, Madrid). Algunas posibilidades de análisis e investigación", Bolskan, 20. Huesca, pp. 277-285.

Quirós Castillo J.A. 2007, "Las aldeas de los historiadores y de los arqueólogos en la Alta Edad Media del Norte Peninsular", Territorio, Sociedad y Poder. Revista de Estudios Medievales 2, pp. 63-86.

Quirós Castillo J.A. 2009 (ed.), The archaeology of early medieval villages in Europe, Documentos de Arqueología e Historia, 1. Bilbao: Servicio Editorial de la UPV/EHU.

Quirós Castillo J.A. 2012 (dir.), Arqueología del campesinado medieval: la aldea de Zaballa. Documentos de Arqueología Medieval 3, Bilbao: Servicio Editorial de la UPV/EHU.

Quirós Castillo J.A., Vigil-Escalera Guirado A. 2006, «Networks of peasant villages between Toledo and Uelegia Alabense, Northwestern Spain (V-Xth centuries)», Archeologia Medievale XXXIII, pp. 79-128. 
Roig Buxó J. 2009, «Asentamientos rurales y poblados tardoantiguos y altomedievales en Cataluña (siglos VI al X)», en J.A. Quirós CASTILlo (ed.), The archaeology of early medieval villages in Europe, Documentos de Arqueología e Historia, 1. Bilbao: Servicio editorial de la Universidad del País Vasco, pp. 207-51.

Sumera F. 1996, «Les premiers fours à pain du Vexin», Vivre en Val-d'Oise, n 40 , pp. 32-37.

Terrats Jiménez N. 2009, «La ocupación tardoantigua de Can Roqueta/TorreRomeu (Sabadell, Barcelona): caracterización de las estructuras», en J.A. Quirós Castillo (ed.), The archaeology of early medieval villages in Europe, Documentos de Arqueología e Historia, 1. Bilbao: Servicio editorial de la Universidad del País Vasco, pp. 303-13.

Tipper J. 2004, The Grubenhaus in Anglo-Saxon England: an analysis and interpretation of the evidence from a most distinctive building type. Landscape Research Center, North Yorkshire.

Vigil-Escalera Guirado A. 1999, «La Indiana (Pinto, Madrid). Estructuras de habitación, almacenamiento, hidráulicas y sepulcrales de los siglos VI-IX en la Marca Media", XXIV Congreso Nacional de Arqueología (Cartagena, 1997), Vol. 5. Murcia, pp. 205-11.

Vigil-Escalera Guirado A. 2000, «Cabañas de época visigoda: evidencias arqueológicas del Sur de Madrid. Tipología, elementos de datación y discusión", Archivo Español de Arqueología 73, pp. 245-74.

Vigil-Escalera Guirado A. 2004, «Memoria de las excavaciones arqueológicas en el yacimiento 'El Rasillo', afectado por el soterramiento de línea eléctrica 400 Kv. (Barajas, Madrid)». Área, S.C.M. Memoria inédita, depositada en la DGPH de la Comunidad de Madrid (XII-04).

Vigil-Escalera Guirado A. 2007a, "Granjas y aldeas altomedievales al Norte de Toledo (450-800 d.C.)", Archivo Español de Arqueología Vol. 80, pp. 239284.

Vigil-Escalera Guirado A. 2007b, «El yacimiento de La Indiana (fase romana)», en Yacimientos arqueológicos de Pinto. 15 años de investigaciones, Madrid, pp. 107-31.

Vigil-Escalera Guirado A. 2007c, «Primeros pasos hacia el análisis de la organización interna de los asentamientos rurales de época visigoda», Zona Arqueológica 8, Vol. II, pp. 366-73.

Vigil-Escalera Guirado A. 2009a, "Las aldeas altomedievales madrileñas y su proceso formativo", en J.A. Quirós Castillo (ed.), The archaeology of early medieval villages in Europe, Documentos de Arqueología e Historia, 1. Bilbao: Servicio editorial de la Universidad del País Vasco, pp. 315-339.

Vigil-Escalera Guirado A. 2009b, Escenarios de emergencia de un paisaje social y político altomedieval en el interior de la peninsula Ibérica durante la quinta centuria. Cerámica, necrópolis rurales y asentamientos encastillados. Tesis doctoral inédita, Universidad del País Vasco (UPV/EHU).

Vigil-Escalera Guirado A. 2009c, «Apuntes sobre la genealogía política de aldeas y granjas altomedievales», en I. Martín Viso (ed.), ¿Tiempos oscuros? Territorios y sociedad en el centro de la Península Ibérica (siglos VII-X), Madrid: Ed. Sílex, pp. 31-44.

Vigil-Escalera A., Hernández L., Hernanz P. 2004, «Memoria de las excavaciones arqueológicas en el yacimiento 'Zarzalejo' (Arroyomolinos, Madrid). 20032004". Memoria inédita, ÁREA, S.C.M., depositada en la DGPH de la Comunidad de Madrid (VI-04).

Vizcaíno Sánchez J. 2007, La presencia bizantina en Hispania (siglos VI-VII). La documentación arqueológica. Antigüedad y Cristianismo: Monografías históricas sobre la Antigüedad Tardía XXIV. Murcia.

Recibido: 3 de julio de 2012 Aceptado: 24 de septiembre de 2012 